\title{
Exogenous interleukin-33 promotes hepatocellular carcinoma growth by remodelling the tumour microenvironment
}

Wenxiu Wang ${ }^{1} \mathbb{D}$, Jun $\mathrm{Wu}^{2}$, Mei Ji ${ }^{2}$ and Changping $\mathrm{Wu}^{1,2^{*}}$

\begin{abstract}
Background: Interleukin-33 (IL-33) is an effective inducer of pro-inflammatory cytokines regulating innate and adaptive immunity. Inflammation could be a double-edged sword, promoting or inhibiting tumour growth. To date, the roles and mechanisms of IL-33 in tumours remain controversial. Here, we examined the effect of exogenous IL-33 on the biological characteristics of hepatocellular carcinoma (HCC) and the possible mechanism of action.

Methods: In this study, IL-33 expression in the tissues of 69 HCC patients was detected and its relationship with prognosis was evaluated. After establishing a mouse HCC model and IL-33 treatment operation, the infiltration of splenic myeloid-derived suppressor (MDSCs), dendritic (DCs), regulatory T, and natural killer (NK) cells was detected by flow cytometry analysis, and the vascular density of the tumour tissues was detected by immunohistochemistry to reveal the mechanism of IL-33 in HCC proliferation. Finally, the Cancer Genome Atlas database was used to analyse Gene Ontology terms the and Kyoto Encyclopaedia of Genes and Genomes pathway. Moreover, the chi-square test, two-tailed unpaired Student's $t$-test, and multiple $t$-tests were performed using SPSS version 23.0 and GraphPad Prism 8.0 software.

Results: The IL-33 expression level was negatively correlated with the overall survival of HCC patients, suggesting its potential clinical significance in the prognosis of HCC. We found that systemic IL-33 administration significantly promoted the tumour size in vivo. Furthermore, the IL-33-treated mice presented decreased frequencies of tumouricidal NK and $\mathrm{CD}_{69}{ }^{+} \mathrm{CD}^{+} \mathrm{T}$ cells. After IL-33 treatment, the incidence of monocytic MDSCs and conventional DCs increased, while that of granulocytic MDSCs decreased. Moreover, IL-33 promoted the formation of intracellular neovascularization. Therefore, IL-33 accelerated HCC progression by increasing the accumulation of immunosuppressive cells and neovascularization formation. Finally, we found that the transcription of IL-33 was closely related to the PI3K-Akt and MAPK pathways in Gene Set Enrichment Analysis plots, which were involved in the tumourigenesis and pathogenesis of HCC.
\end{abstract}

Conclusions: Taken together, IL-33 may be a key tumour promoter of HCC proliferation and tumourigenicity, an important mediator, and a potential therapeutic target for regulating HCC progression.

Keywords: Interleukin-33, Hepatocellular carcinoma, Tumourigenesis

*Correspondence: wcpjjt@163.com

2 Department of Oncology, The Third Affiliated Hospital of Soochow University, 185 Juqian Street, Changzhou 213003, Jiangsu, China

Full list of author information is available at the end of the article

\begin{abstract}
Background
Interleukin-33 (IL-33) has been described as a potent promoter of type II immunity that triggers an innate immune response to allergic inflammation and parasitic infections [1]. Since 2005 the function of IL-33, as a pleiotropic cytokine, has been widely studied. IL-33 has been
\end{abstract}


found to be involved in the occurrence of many diseases, such as atherosclerosis [2] and obesity [3], and plays a pro-inflammatory role in asthma [4] and antigen-induced arthritis [5]. Endogenous IL-33 is released into the extracellular system, which alerts the immune system after cell damage or necrosis. Activated IL-33 binds to a co-receptor, a heterodimer composed of ST2 and IL1RAP, and initiates inflammatory pathways [6]. In addition, IL-33 recruits signal adapters and kinases to activate transcription factors in tumour cells, which produce the tumourassociated inflammatory microenvironment [7].

ST2 is an IL-33 specific receptor encoded by the gene IL1RL1, expressed mainly by immune cells [8]. The combination of IL-33 and ST2 activates a variety of ST2 ${ }^{+}$ immune cells including the group 2 innate lymphoid (ILC2), regulatory $\mathrm{T}$ (Tregs), and dendritic cells (DCs), thus, inducing the secretion of various chemokines and proinflammatory cytokines and regulating local and systemic immunity [9]. The involvement of IL-33 in innate and adaptive immunity is bidirectional. When exposed to IL-33, DCs could promote the proliferation and differentiation of naive $C D 4^{+} \mathrm{T}$ cells [10]. IL-33 could also indirectly regulate Tregs by activating ILC2s, DCs, or mast cells [11]. Therefore, IL-33 is the main regulator of Tregs and ILC2s, and has multiple activities in type I, type II, and immune regulation [12].

Further, IL-33 promotes inflammatory events in tumours and activates pro- or anti-tumour responses [13]. In pancreatic cancer, IL-33 is responsible for the upregulation of proinflammatory cytokines, such IL-6 and IL-8 [14]. Transgenic IL-33 activates natural killer (NK) and T cells, resulting in growth inhibition and metastasis of melanoma and lung cancer [15]. The IL-33/ ST2 pathway upregulates CD40L and suppresses the growth of murine colon cancer [16]. However, IL-33 enhances type II immune response accelerating tumour progression in tumour-bearing animals [17]. Colon cancer transfection with IL-33 promotes tumour metastasis by accumulating myeloid-derived suppressor cells (MDSCs) to regulate the tumour microenvironment (TME) [18]. ST2 ${ }^{+}$tumour-associated macrophages are recruited into the TME by CXCR3 to suppress host immunity and ST2 knockout mice inhibit colorectal cancer growth in combination with anti-PD-1 antibody [19]. Tumour-derived IL-33 activates mast cells and macrophages, promoting the development of gastric cancer [20]. Therefore, the role of IL-33 in cancer remains controversial. In a previous study on hepatocellular carcinoma (HCC), the RS3821204 genotype of plasma ST2 was positively correlated with HCC risk in Chinese individuals [21]. Interestingly, IL-33 in stromal cells regulated by the pDGF-BB-SOX7 axis promoted HCC metastasis through tumour-associated macrophages [22]. However, tumour-infiltrating effector-memory $\mathrm{CD}^{+} \mathrm{T}$ cells in surgically resected tissues producing IL-33 could prolong the survival of HCC patients [23]. In addition, IL-33 released by the liver inhibits HCC growth by promoting $\mathrm{T}$ cell response [24]. Therefore, the effect of IL-33 on HCC by the regulation of the immune system should be further studied.

Here, we examined the effect of exogenous IL-33 on the biological characteristics of HCC in human tissues and in mice, and predicted the most relevant pathways of IL-33-associated genes. Our study explored the correlation between IL-33 expression and the prognosis of patients, suggesting that IL-33 may be a marker of poor HCC prognosis. Moreover, the mechanism of IL-33 was explained in terms of tumour microenvironment remodelling, secretion of factors promoting tumour proliferation, and microvascular density. Finally, we proposed the scope for future development direction and research regarding the mechanisms and roles of IL-33.

\section{Methods \\ Samples}

The HCC tissue array was purchased from Shanghai Outdo Biotech (Shanghai, China). The cases were enrolled based on their clinical follow-up data and the absence of preoperative history of chemoradiotherapy. The Edmondson and Steiner classification was used to grade the tumour [25]. The TNM staging was used in accordance with the American Joint Committee on Cancer guidelines. The age of the $69 \mathrm{HCC}$ patients in the HCC tissue array ranged from 16 to 75 years (mean age, 49 years). The follow-up time ranged from 0.36 to 155 months (mean time, 32.8 months). Sixty-nine paracancer tissues pathologically diagnosed as normal were obtained from tissues $\geq 5 \mathrm{~cm}$ away from the tumour of HCC patients. Five para-cancer tissue samples were damaged during the heat-induced antigen retrieval process. Finally, a total of $69 \mathrm{HCC}$ patients and 64 paired para-carcinoma controls were included in the analysis. Information on the relationship between IL-33 and clinicopathological features of the HCC patients is presented in Tables 1 and 2. The study protocol was approved by the ethics committee of the Third Affiliated Hospital of Soochow University and conducted in accordance with the Declaration of Helsinki. All patients provided informed consent for participation.

\section{Cell culture}

Hepa1-6, an HCC cell line in mice, was purchased from the National Platform for Experimental Cell Resources (Beijing, China). Hepa1-6 cells were maintained in DMEM (Hyclone Laboratories, Logan, UT, USA), and $10 \%(\mathrm{v} / \mathrm{v})$ foetal bovine serum (ExCell Bio, Clearwater, 
Table 1 Correlation between IL-33 expression and clinicopathological characteristics of HCC

\begin{tabular}{|c|c|c|c|c|c|}
\hline \multirow{2}{*}{$\begin{array}{l}\text { Clinicopathological } \\
\text { characteristics }\end{array}$} & \multirow[t]{2}{*}{ Cases } & \multicolumn{2}{|c|}{ IL-33 expression level } & \multirow[t]{2}{*}{$x^{2}$} & \multirow[t]{2}{*}{ P value } \\
\hline & & Low $(\mathrm{H}$-score < 68) & High (H-score $\geq 68$ ) & & \\
\hline \multicolumn{6}{|l|}{ Age (years) } \\
\hline 60 & 55 & 28 & 27 & 0.289 & 0.591 \\
\hline$\geq 60$ & 14 & 6 & 8 & & \\
\hline \multicolumn{6}{|l|}{ Sex } \\
\hline Male & 59 & 28 & 31 & 0.538 & 0.463 \\
\hline Female & 10 & 6 & 4 & & \\
\hline \multicolumn{6}{|l|}{ Number of tumours } \\
\hline Single & 40 & 18 & 22 & 0.696 & 0.404 \\
\hline Multiple & 29 & 16 & 13 & & \\
\hline \multicolumn{6}{|l|}{ Tumour size (cm) } \\
\hline$\leq 5$ & 18 & 11 & 7 & 1.365 & 0.243 \\
\hline$>5$ & 51 & 23 & 28 & & \\
\hline \multicolumn{6}{|l|}{ Capsule integrity } \\
\hline No & 39 & 20 & 19 & 0.145 & 0.704 \\
\hline Yes & 30 & 14 & 16 & & \\
\hline \multicolumn{6}{|l|}{ HBV positivity } \\
\hline Negative & 8 & 1 & 7 & 4.896 & 0.027 \\
\hline Positive & 61 & 33 & 28 & & \\
\hline \multicolumn{6}{|l|}{ TNM stage } \\
\hline $1+\|$ & 30 & 13 & 17 & 0.75 & 0.387 \\
\hline$I I I+I V$ & 39 & 21 & 18 & & \\
\hline \multicolumn{6}{|l|}{ Edmondson type } \\
\hline $1+11$ & 45 & 24 & 21 & 0.852 & 0.356 \\
\hline III & 24 & 10 & 14 & & \\
\hline \multicolumn{6}{|l|}{ Cirrhosis background } \\
\hline Absent & 11 & 3 & 8 & 2.535 & 0.111 \\
\hline Present & 58 & 31 & 27 & & \\
\hline \multicolumn{6}{|l|}{ Venous invasion } \\
\hline No & 61 & 32 & 29 & 2.133 & 0.144 \\
\hline Yes & 8 & 2 & 6 & & \\
\hline \multicolumn{6}{|l|}{ Recurrence } \\
\hline No & 46 & 24 & 22 & 0.464 & 0.496 \\
\hline Yes & 23 & 10 & 13 & & \\
\hline \multicolumn{6}{|l|}{ Metastasis } \\
\hline No & 65 & 33 & 32 & 1.001 & 0.317 \\
\hline Yes & 4 & 1 & 3 & & \\
\hline
\end{tabular}

Italic font indicates significant differences $(P<0.05)$

FL, USA) was added. Cell lines were routinely examined for cell morphology and mycoplasma.

\section{Experimental animals}

Several female C57BL/6 mice (age, 6-8 weeks) were obtained from Shanghai Laboratory Animal Centre (Shanghai, China). These mice were placed in specific pathogen-free facilities. All animal treatment procedures, such as mouse care and experimental procedures, were reviewed by the Animal Ethics Committee of The Third Affiliated Hospital of Soochow University. The animals were fed in strict accordance with operating procedures and provided a clean and comfortable living environment; the animals were handled at appropriate intervals, and measures were taken to minimise animal suffering. 
Table 2 Cox-regression analysis of the correlation between IL-33 expression and prognostic parameters in HCC patients

\begin{tabular}{|c|c|c|c|c|}
\hline \multirow[t]{2}{*}{ Parameter } & \multicolumn{2}{|l|}{ Univariate analysis } & \multicolumn{2}{|l|}{ Multivariate analysis } \\
\hline & $\mathrm{HR}(95 \% \mathrm{Cl})$ & P value & HR (95\% Cl) & $P$ value \\
\hline \multicolumn{5}{|l|}{ Age (year) } \\
\hline$(\geq 60$ vs. $<60)$ & $0.873(0.452-1.684)$ & 0.685 & $1.681(0.797-3.543)$ & 0.172 \\
\hline \multicolumn{5}{|l|}{ Number of tumours } \\
\hline (Multiplies vs. Single) & $1.579(0.937-2.659)$ & 0.086 & $1.863(1.053-3.297)$ & 0.033 \\
\hline \multicolumn{5}{|l|}{ Sex } \\
\hline (Female vs. male) & $0.341(0.135-0.861)$ & 0.023 & $0.351(0.131-0.939)$ & 0.037 \\
\hline \multicolumn{5}{|l|}{ Tumour size $(\mathrm{cm})$} \\
\hline$(>5$ vs. $\leq 5)$ & $1.576(0.862-2.883)$ & 0.14 & $1.333(0.680-2.616)$ & 0.403 \\
\hline \multicolumn{5}{|l|}{ Capsule integrity } \\
\hline (Yes vs. no) & $0.513(0.300-0.879)$ & 0.015 & $0.637(0.358-1.131)$ & 0.124 \\
\hline \multicolumn{5}{|l|}{ Venous invasion } \\
\hline (Yes vs. no) & $2.54(1.217-5.302)$ & 0.013 & $2.596(1.140-5.910)$ & 0.023 \\
\hline \multicolumn{5}{|l|}{ IL-33 expression } \\
\hline (High vs. low) & $1.890(1.111-3.216)$ & 0.019 & $1.906(1.099-3.305)$ & 0.022 \\
\hline
\end{tabular}

Italic font indicates significant differences $(P<0.05)$

$H R$ hazard ratio, $\mathrm{Cl}$ confidence interval

\section{HCC model}

A murine HCC model was established in the current study. A suspension of Hepa1-6 cells was prepared using phosphate-buffered saline (PBS), before implantation. Then, the syngeneic female mice (age, 6-8 weeks) were anesthetised with chloral hydrate. A total of $8 \times 10^{6}$ Hepa1- 6 cells resuspended into $80 \mu \mathrm{L}$ PBS were injected subcutaneously on day 0 into the back of the mice. Then, the mice were injected with the murine recombinant IL-33 protein $(0.4 \mu \mathrm{g} /$ mouse; PeproTech, Cranbury, NJ, USA) or PBS intraperitoneally five times every other day starting from day 3. Finally, the mice were sacrificed, and tumour volumes were calculated using the following formula:

$$
\text { Tumour volume }=\left(\text { length } \times \text { width }^{2}\right) / 2 .
$$

\section{Immunohistochemistry}

Tissue sections were incubated with primary antibodies for anti-human IL-33 (R\&D Systems, Minneapolis, MN, USA), anti-mouse Ki67, CD31, SA1009, vascular endothelial growth factor (VEGF; all obtained from Abcam, Cambridge, UK), or matching IgG isotypes overnight. Then, the sections were conjugated with secondary antibody. For the tissue array, Pannoramic MIDI (3DHISTECH, Budapest, Hungary) was used to scan the tissue points. All the immunohistochemical reactions were evaluated by three experienced pathologists who were blinded to clinical information according to the H-score method [26]. The H-score was calculated as follows:

$$
\begin{aligned}
\mathrm{H} \text {-score }= & (\text { percentage of cells of weak intensity } \times 1) \\
& +(\text { percentage of cells of moderate intensity } \times 2) \\
& +(\text { percentage of cells of stringe intensity } \times 3)
\end{aligned}
$$

The maximum $\mathrm{H}$-score was defined as 300 , based on $100 \%$ cells exhibiting strong intensity. The experiment was independently repeated three times.

\section{Cell proliferation assay}

The cell proliferation potential was performed with the cell counting kit-8 assay (CCK8; Invitrogen, Waltham, MA, USA) in vitro. Hepa1-6 cells (5000 cells per well plate) were plated to 96 -well plates with IL-33 concentrations of $10,20,50$, and $100 \mathrm{ng} / \mathrm{ml}$ for $48 \mathrm{~h}$ and, then, detected by CCK-8 (Dojindo Laboratories, Kumamoto, Japan) with a microplate reader. The experiment was independently repeated three times.

\section{Quantitative reverse-transcription polymerase chain reaction ( $q P C R)$}

RNA from murine HCC was extracted with Trizol reagent (Invitrogen). Especially, $1 \mu \mathrm{g}$ RNA was reverse transcribed into cDNA with RevertAid First Strand cDNA Synthesis Kit (Servicebio, Wuhan, China) and, then, qPCR was performed using FastStart Universal SYBR Green Master (Servicebio) with the Prism 7900H system (Thermo Fisher Scientific, Waltham, MA, USA). We calculated the relative quantification of mRNA expression 
using the delta-delta Ct method [27] and normalised the PCRs utilising GAPDH as the reference gene. The primers are listed in Additional file 1: Table S1. The experiment was independently repeated three times.

\section{Flow cytometric analyses}

Single cell suspensions of splenocytes and fresh tumour tissues from mice were incubated with fluorochromelabelled anti-mouse antibodies specific for CD45, CD3, CD4, CD8, NK1.1, Ly6G, CD69, CD44, CD62L, CD11b, CD11c, Gr1, Ly6C, major histocompatibility complex (MHC) class II, B220, or isotype-matched controls (eBioscience, Thermo Fisher Scientific). For the foxp3 nuclear protein, cells were permeabilised using Transcription Factor Staining Buffer Set (Invitrogen) for $30 \mathrm{~min}$. Then, they were analysed using FACSCalibur Flow Cytometer (BD Pharmingen, San Jose, CA, USA). The experiment was independently repeated three times.

\section{Statistical analysis}

The chi-square, two-tailed unpaired Student's $t$-, and multiple $t$-tests were performed using SPSS (version 23.0; IBM Corp., Armonk, NY, USA) and GraphPad Prism 8.0 (San Diego, CA, USA) software. Overall survival (OS) and disease-free survival (DFS) curves were conducted with the log-rank test according to the Kaplan-Meier method. Data (means \pm standard deviations) were repeated at least three independent times. The statistical significance level was set at $\mathrm{P}<0.05$. Gene Ontology $(\mathrm{GO})$, Kyoto Encyclopaedia of Genes and Genomes (KEGG), and Gene Set Enrichment Analysis (GSEA) were performed with $R$ package clusterProfiler, $R$ package DOSE, and $R$ package org. Hs.eg.db (R Foundation for Statistical Computing, Vienna, Austria). For GSEA plots, false discovery rate $\mathrm{q}$-value (P. adjust) $\leq 0.25$, nominal $\mathrm{P}$-value $<0.01$, and $\mid$ normalised enrichment score $\mid \geq 1$ were regarded as significant.

\section{Results}

\section{IL-33 is upregulated in HCC}

To determine the role of IL-33 in HCC patients, we initially explored IL-33 expression in a tissue array containing $69 \mathrm{HCC}$ and 64 paired adjacent normal tissue samples (five para-cancer tissue samples were damaged during the heat-induced antigen retrieval process). Immunostaining with different intensities of IL-33 was shown in the cytoplasm in HCC tissues (Fig. 1a; Left-strong, moderate, weak). Weak or negative staining (Fig. 1a; right) of IL-33 was found in the adjacent normal tissues. Through the quantitative analysis of IL-33 expression, we found that it was upregulated in the HCC tissue compared with that in the adjacent tissue (Fig. 1b). To exclude the influence of individual differences, we further analysed IL-33 expression in 64 paired $\mathrm{HCC}$ and adjacent para-cancer tissues in this dataset and found that it was significantly upregulated in the 44 paired HCC tissues compared with the adjacent tissues (Fig. 1c).

\section{High IL-33 expression in HCC correlates with poor patient survival and advanced clinicopathological features}

To understand the clinical implications of upregulating IL-33, we analysed the correlation between IL-33 expression and clinicopathological characteristics in HCC patients. Higher IL-33 expression was significantly correlated with Hepatitis B virus positivity $\left(X^{2}=4.896\right.$; $\mathrm{P}=0.027$ ) but not with sex, tumour size, TNM stage, or differentiation (Table 1).

We further analysed the clinical follow-up time of 69 HCC patients. Compared with patients with low IL-33 expression, those with high IL-33 expression had significantly shorter OS $(\mathrm{P}=0.0145$; hazard ratio $[\mathrm{HR}], 1.853$; 95\% confidence interval [CI] 1.096-3.134) (Fig. 1d). Moreover, the differences were even more significant in the DFS of HCC patients ( $\mathrm{P}=0.0145$; HR, 2.428; $95 \%$ CI 1.107-5.326) (Fig. 1e). We also analysed the effect of IL-33 expression on the prognosis of HCC. In univariate Cox regression analyses, high expression of IL-33 was associated with increased death risk in HCC patients $(\mathrm{P}=0.019$; Table 2). Furthermore, IL-33 expression in HCC patients $(\mathrm{P}=0.022)$ could be identified as an independent prognostic predictor in multivariate Cox regression analysis (Table 2).

\section{Exogenous IL-33 leads to accelerated HCC growth}

To examine the effect of IL-33 on tumour progression, the murine HCC model was established in Hepa1-6 cells. HCC developed aggressively in the IL-33-treated experimental group, as reflected by the gross view of the mice (Fig. 2a) and tumour (Fig. 2b, Additional file 2: Figure S1a). The tumour weight was significantly higher in the IL-33-treated than in the PBS-treated mice (Fig. 2c, Additional file 2: Figure S1b). In addition, the tumour volume increased rapidly after IL-33 treatment, with significant difference at multiple time points compared with that in untreated mice (Fig. 2d, Additional file 3: Figure S2c). Therefore, IL-33 treatment was found to dramatically promote Hepa1-6 growth in vivo.

Although no significant difference was observed in haematoxylin and eosin (H\&E) staining between mice treated with IL-33 or those that were not, it was clear that Hepa1-6 cells were loosely arranged with large nuclear malformation and imbalance of nuclear plasma in these mice (Fig. 2e, Additional file 2: Figure S1d). The staining intensity of the proliferative marker Ki67 in the IL33-treated experimental group was stronger and more significant compared with that in the control group 

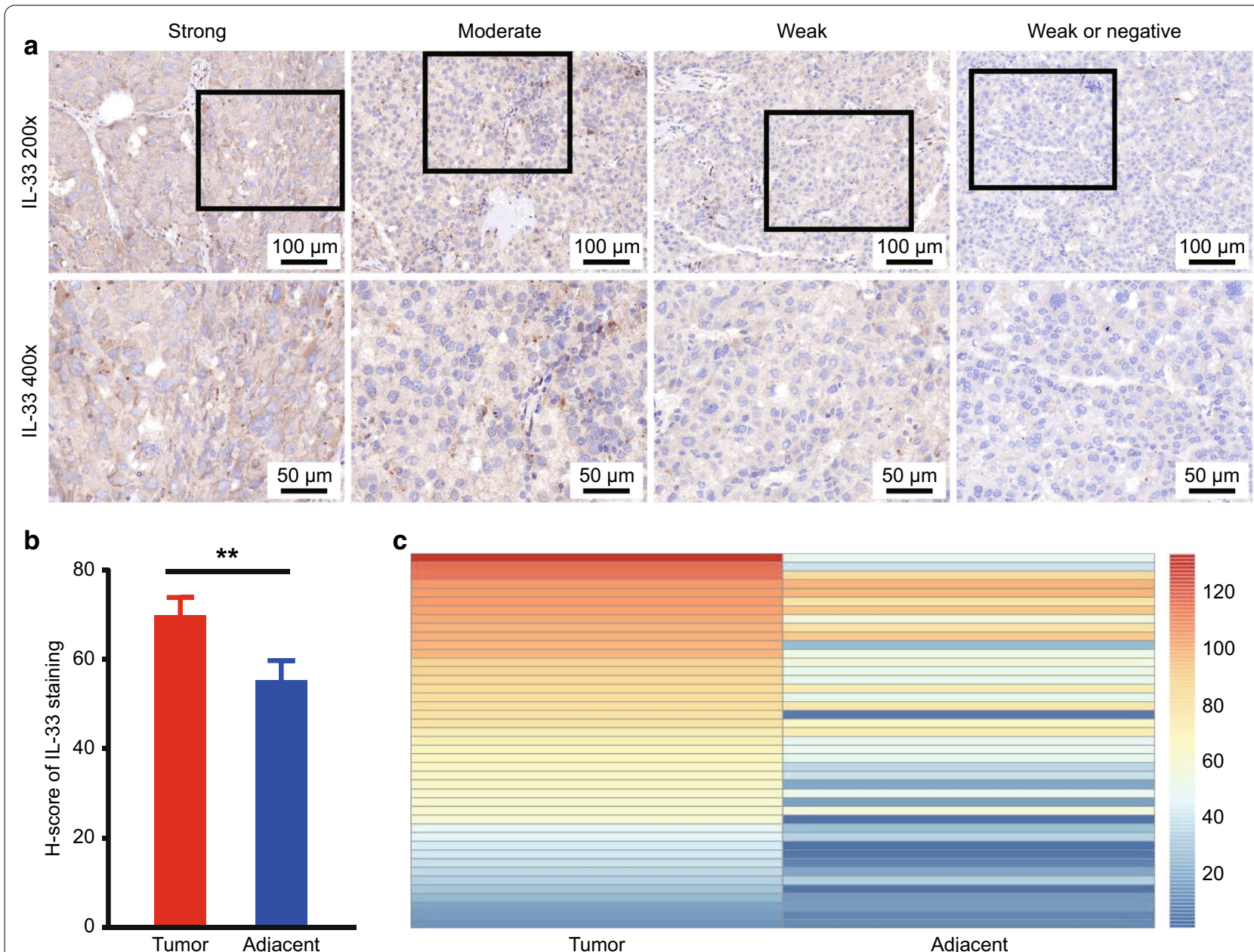

C
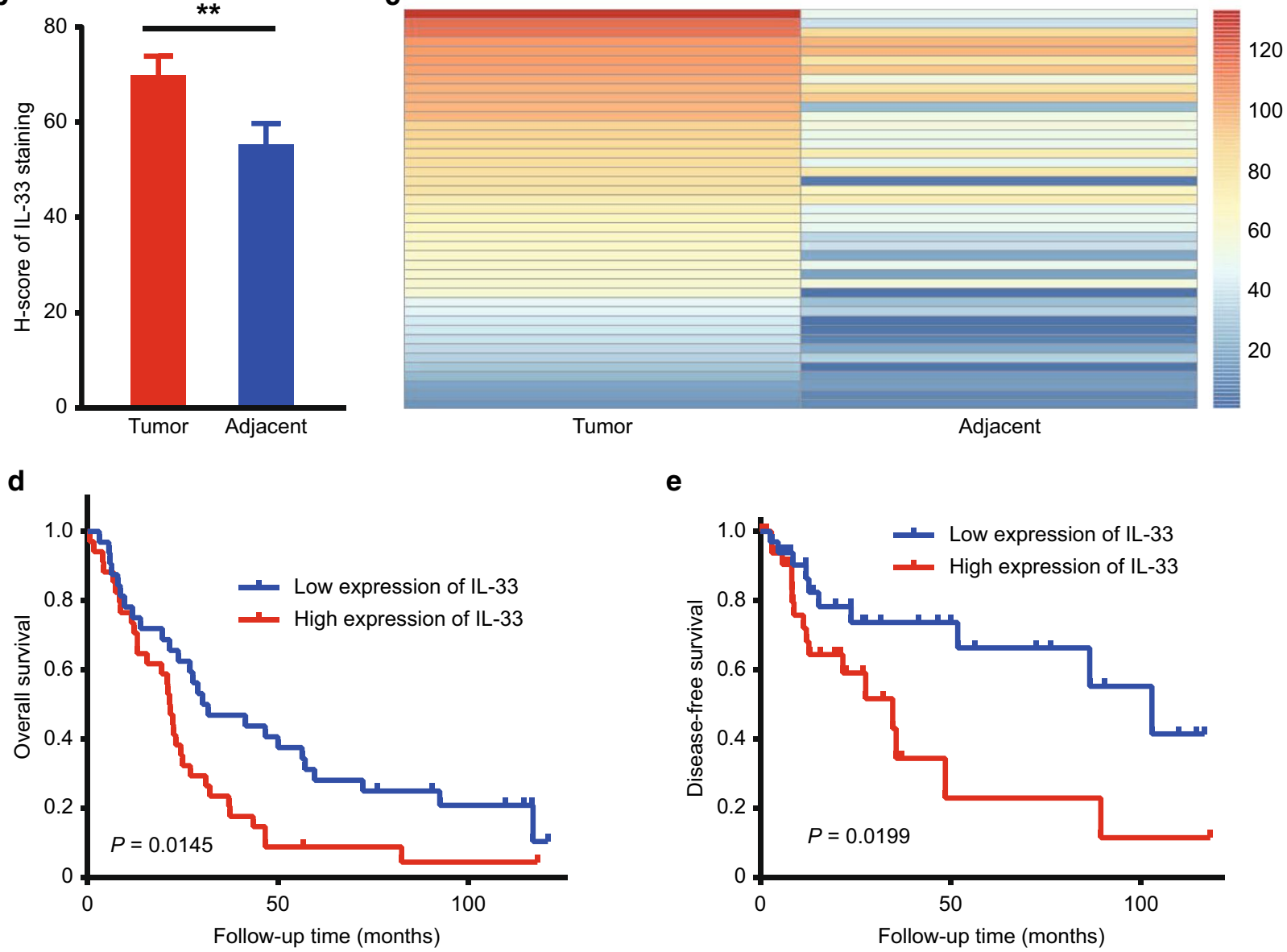

Fig. 1 IL-33 expression was upregulated in human HCC tissues and was associated with poor patient survival. a The representative IHC images of IL-33 expression in HCC (left-strong, moderate, weak) and in adjacent normal tissues (right-weak or negative) were presented. b IL-33 expression was frequently upregulated in $69 \mathrm{HCC}$ tissues compared with that in the 64 adjacent para-carcinoma tissues. c After excluding the influence of individual differences, the expression of IL-33 was analysed in 64 paired HCC and adjacent para-cancer tissues in this dataset. d Kaplan-Meier OS and e DFS curves for $69 \mathrm{HCC}$ patients were analysed based on the H-score of IL-33 staining. HCC hepatocellular carcinoma, IL-33 interleukin-33, OS overall survival, DFS disease-free survival 

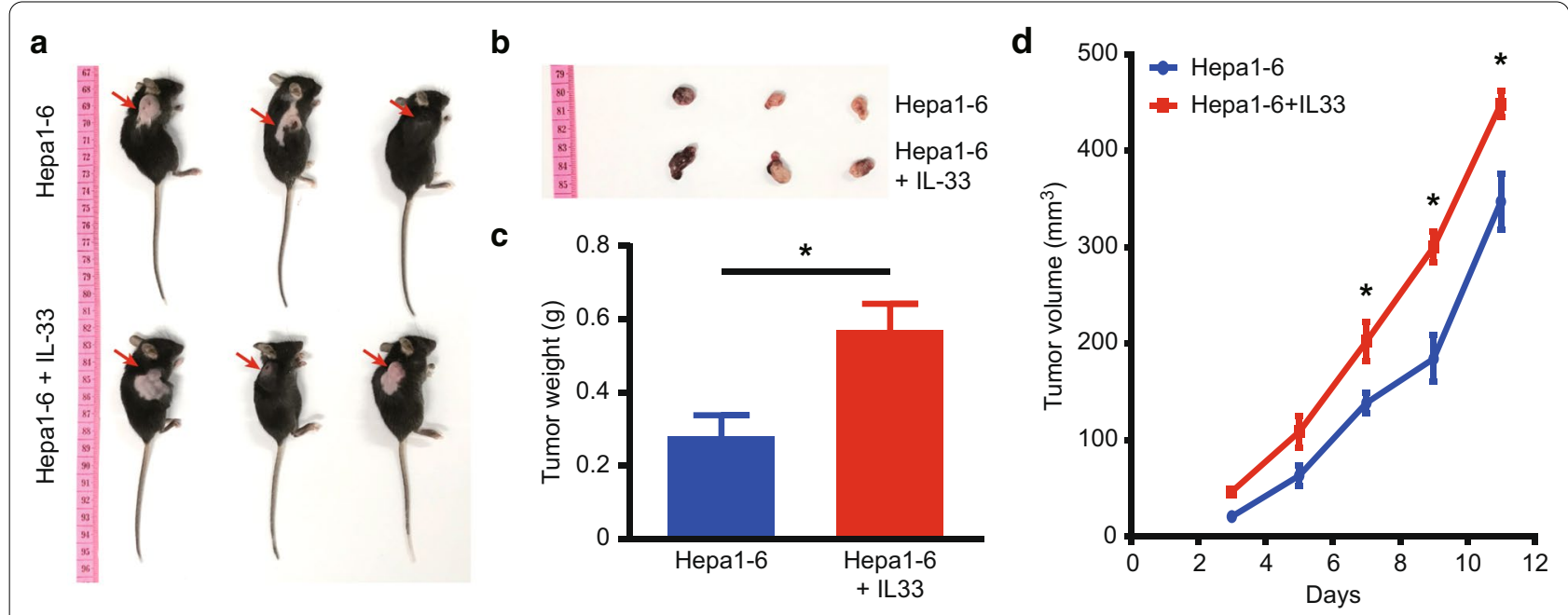

e

Hepa1-6

Hepa1-6 + IL-33

g

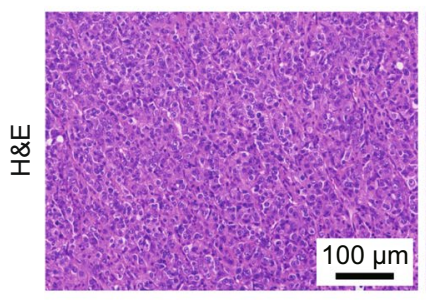

f


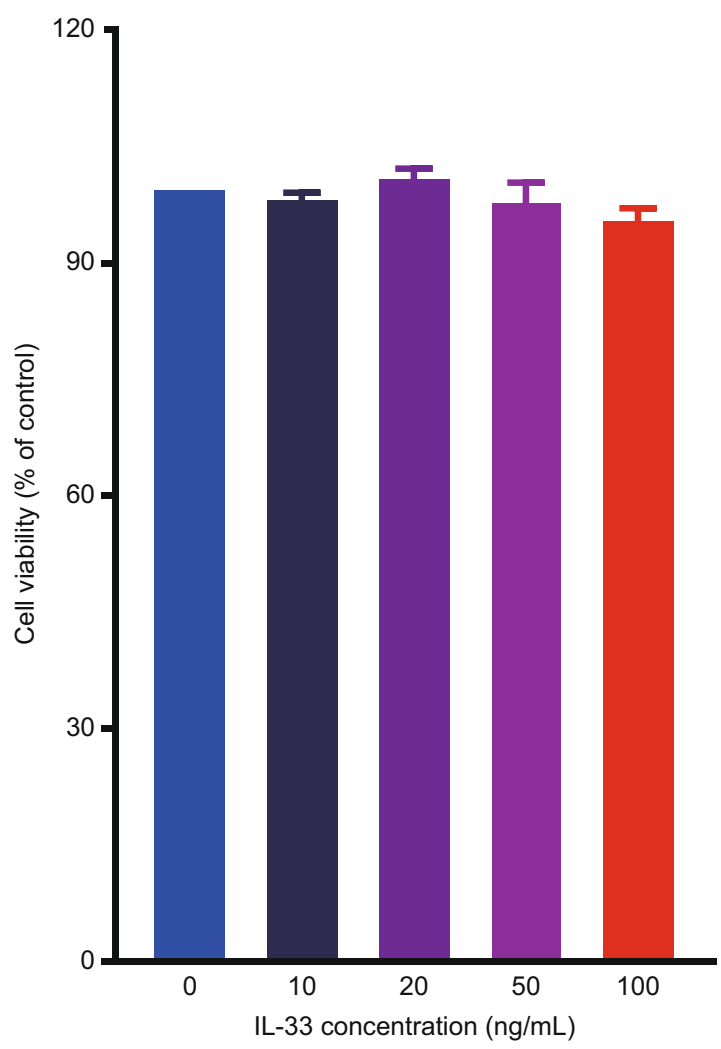

Fig. 2 LL-33 enhanced HCC tumourigenesis. C57BL/6 mice were injected subcutaneously with Hepa1-6 cells $\left(8 \times 10^{6}\right)$ and treated with or without IL-33 protein $(0.4 \mathrm{\mu g} / \mathrm{mouse})$ in PBS intraperitoneally every other day. $\mathbf{a}$ Gross view of mice and $\mathbf{b}$ tumours after euthanasia of mice. $\mathbf{c}$ An histogram of tumour weight was presented from both groups of mice. $\mathbf{d}$ Tumour volume changed over time in two groups. $\mathbf{e}$ H\&E staining images of tumour tissues from both groups of mice were presented. $\mathbf{f}$ Ki67 protein expression was detected by IHC. $\mathbf{g}$ The effect of IL-33 on Hepa1-6 cell proliferation was observed by CCK8 in vitro. PBS phosphate-buffered saline, H\&E haematoxylin and eosin, IHC immunohistochemistry, CCK8 cell counting kit 8

(Fig. 2f, Additional file 2: Figure S1e). This suggested that IL-33 augmented the proliferation of Hepa1-6 HCC tissues in mice. However, IL-33 had no direct effect on the proliferation of Hepa1-6 cells in vitro (Fig. 2g). The efficacy of IL-33 may be partly attributable to tumour immunogenicity rather than to the changing intrinsic characteristics of tumour cells, as reported in literature [28]. 


\section{IL-33 may remodel the tumour microenvironment (TME)}

To investigate whether exogenous IL-33 affects HCC occurrence by regulating the immune system, we examined immune cell phenotypes in the spleen and tumours of Hepa1-6-bearing mice treated with IL-33 and those who were not (Fig. 3). IL-33 administration markedly increased $\mathrm{CD}_{4} 5^{+}$leukocyte immune cell infiltration on day 11 after the tumour challenge (Fig. 3a). Moreover, we observed a decrease in frequencies of intratumoural NK cells in tumour-bearing mice with IL-33 treatment (Fig. 3a). The percentage of activated $\mathrm{CD} 69^{+} \mathrm{CD}^{+} \mathrm{T}$ cells was remarkably downregulated in the IL-33-treated group (Fig. 3b). However, effector $\left(\mathrm{CD} 44^{+} \mathrm{CD} 62 \mathrm{~L}^{-}\right)$or naive $\left(\mathrm{CD}_{4} 4^{-} \mathrm{CD}^{2} \mathrm{~L}^{+}\right) \mathrm{CD}^{+} \mathrm{T}$ and $\mathrm{CD} 8^{+} \mathrm{T}$ cells were not affected by IL-33 administration (Additional file 3: Figure S2a, b). In addition, no significant difference was observed in the mRNA levels of IFN- $\gamma$ between the two groups (Additional file 3: Figure S2c). These results demonstrated that IL-33 may promote tumour progression by reducing the proportion of $\mathrm{CD}^{+} \mathrm{T}$ and NK cells in vivo.

Meanwhile, IL-33 increased the splenic infiltration of immunosuppressive cells in tumour-bearing mice. Tregs, which play critical roles in immunosuppression, were significantly increased in spleens when compared with the corresponding in PBS-treated mice (Fig. 3c), but not in the tumour tissue (Fig. 3a). Moreover, IL-33-treated mice exhibited a pronounced increase in $\mathrm{CD} 11 \mathrm{c}^{-} \mathrm{CD} 11 \mathrm{~b}^{+} \mathrm{Gr} 1^{+}$ MDSCs, which led to tumour immune escape and tumourigenesis (Fig. 3d). Monocytic MDSCs increased and granulocytic MDSCs decreased after IL-33 treatment in tumour-bearing mice compared with that in the control group, albeit not significantly (Fig. 3e). Furthermore, IL-33 administration influenced the incidence of splenic DC subpopulations. Significant increases in the percentage of $C D 11 c^{+}$and $C D 11 c^{+} C D 11 B^{+}$DCs were found in tumour-bearing mice treated with IL-33 (Fig. 3f, g).

Moreover, the MHC II expressed on DCs had an effect on evoking efficient anti-tumour immune responses. MHC II expression in splenic DCs decreased in response to IL-33 administration, thus, blocking DC maturation and their cross-presentation ability (Fig. 3h). In addition, IL-33 treatment reduced the percentage of

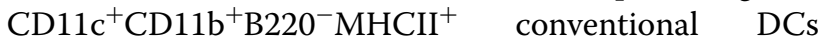
(Fig. 3i).

\section{IL-33 induces tumour-promoting cytokine and neomicrovessel formation}

To investigate the influence of exogenous IL-33 on proinflammatory factors, such as IL-6, IL-1 $\beta$, and tumour necrosis factor (TNF)- $\alpha$, we measured their mRNA expressions, which are known to stimulate tumour proliferation and angiogenesis [29]. Although there was a slight difference in the IL- 6 and TNF- $\alpha$ mRNA levels, the
IL-1 $\beta$ cytokine levels were elevated in tumours injected with IL-33 (Fig. 4a). Then, we detected the chemokines that recruited myeloid cells into the TME and mediated angiogenesis [30]. The results showed that the mRNA levels of Csf2, Ccl2, Ccl5, and Cxcl1 chemokines significantly increased after IL-33 treatment (Fig. 4b). In addition, exogenous IL-33 enhanced the immunostaining intensity and mRNA levels of S100A9 (Fig. 4c, d), which induced epithelial-mesenchymal transition and led to tumour occurrence [31]. Therefore, IL-33 may induce chemokines (e.g. Cxcl1), which enhanced the recruitment of myeloid cells secreting S100A9 to promote tumour progression.

Moreover, the microvascular density was approximately higher in experimental than in untreated mice (Fig. 4g), indicating significant microvascular generation. A past study showed that IL-33 could initiate vascular remodelling through upregulating VEGF expression in hypoxic pulmonary hypertension [32]. As a key signal to stimulate angiogenesis, VEGF was highly expressed after IL-33 treatment, supporting our previous conclusion (Fig. 4e, f). In addition, IL-33 elevated the immunohistochemistry (IHC) staining intensity of endothelial cell marker like CD31, an indicator of neomicrovessels (i.e. blood and lymphatic vessels), which suggested that active angiogenesis and lymphangiogenesis occurred in IL-33-treated tumours (Fig. 4h).

\section{Predictions of the functions and pathways of IL-33 and the genes significantly associated with IL-33 alterations}

To explore the functions of IL-33 and the genes that were significantly associated with IL-33 alterations, GO and KEGG pathway enrichment analyses were performed. As presented in Fig. 5a-c, biological processes, such as GO: 0030198 (extracellular matrix organization), GO: 0043062 (extracellular structure organization), GO: 0043542 (endothelial cell migration), GO: 0001667 (ameboid-type cell migration), and GO: 0090130 (tissue migration), were remarkably regulated by the IL-33 alterations in HCC patients (Fig. 5a). Cellular components and molecular functions including GO: 0062023 (collagen-containing extracellular matrix), GO: 0005911 (cell-cell junction), GO: 0005201 (extracellular matrix structural constituent), and GO: 0005539 (glycosaminoglycan binding) were significantly associated with these IL-33 alterations (Fig. 5b, c). The KEGG pathway analysis showed that the most enriched pathways were 04151 (PI3K-Akt signalling pathway), 04022 (cGMP-PKG signalling pathway), 04020 (Calcium signalling pathway), 04611 (Platelet activation), and 04371 (Apelin signalling pathway), which were associated with tumourigenesis and HCC progression (Fig. 5d). 


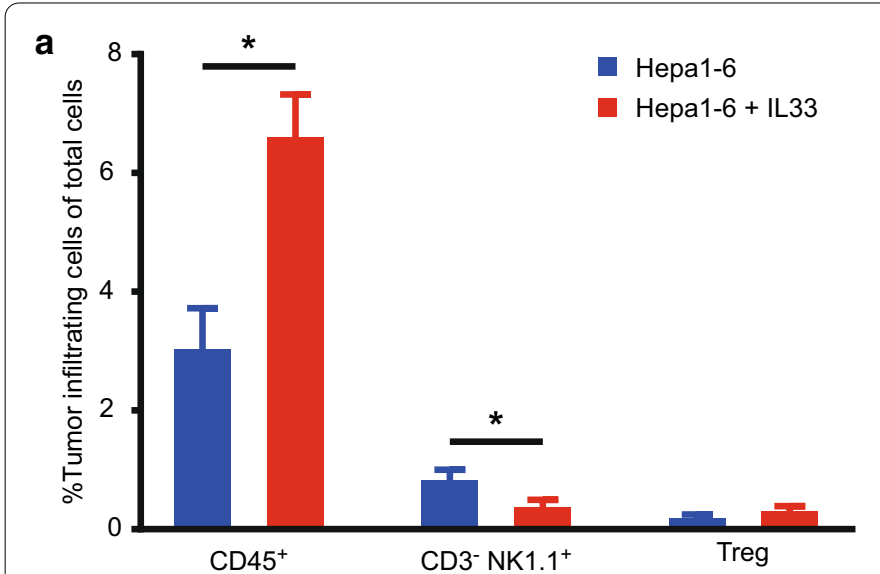

b

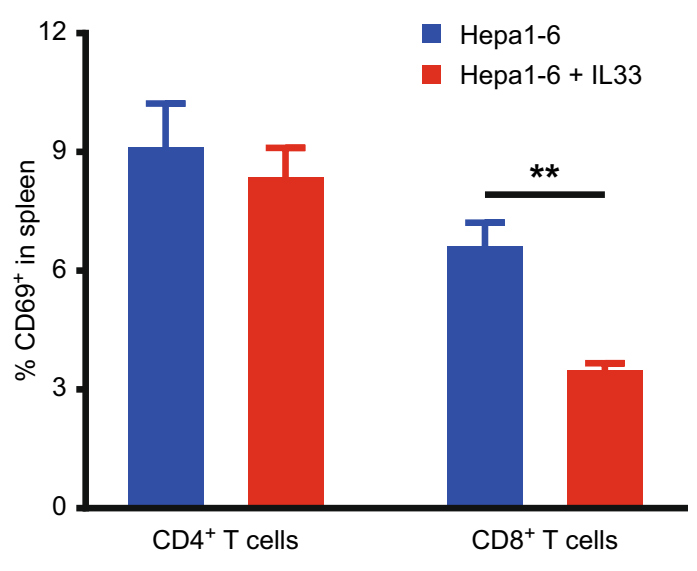

e

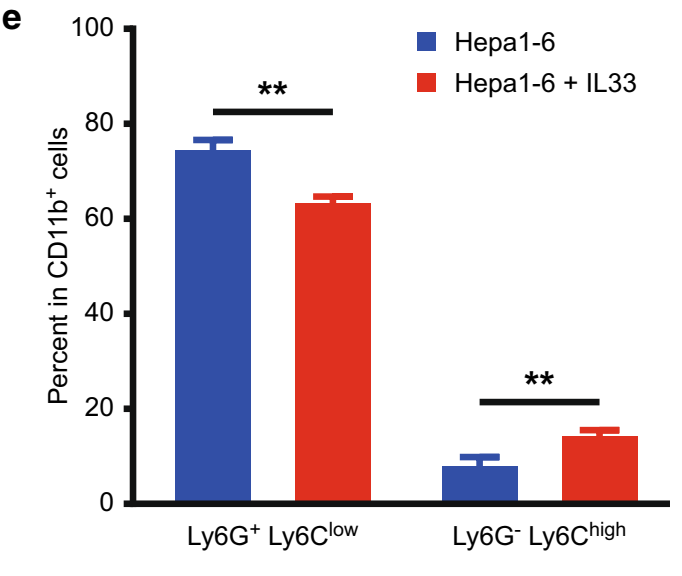

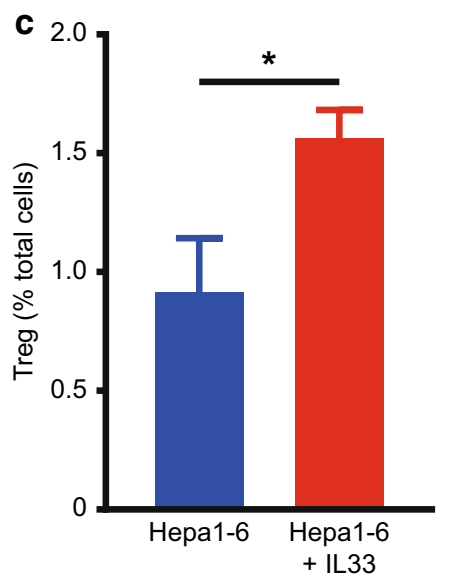
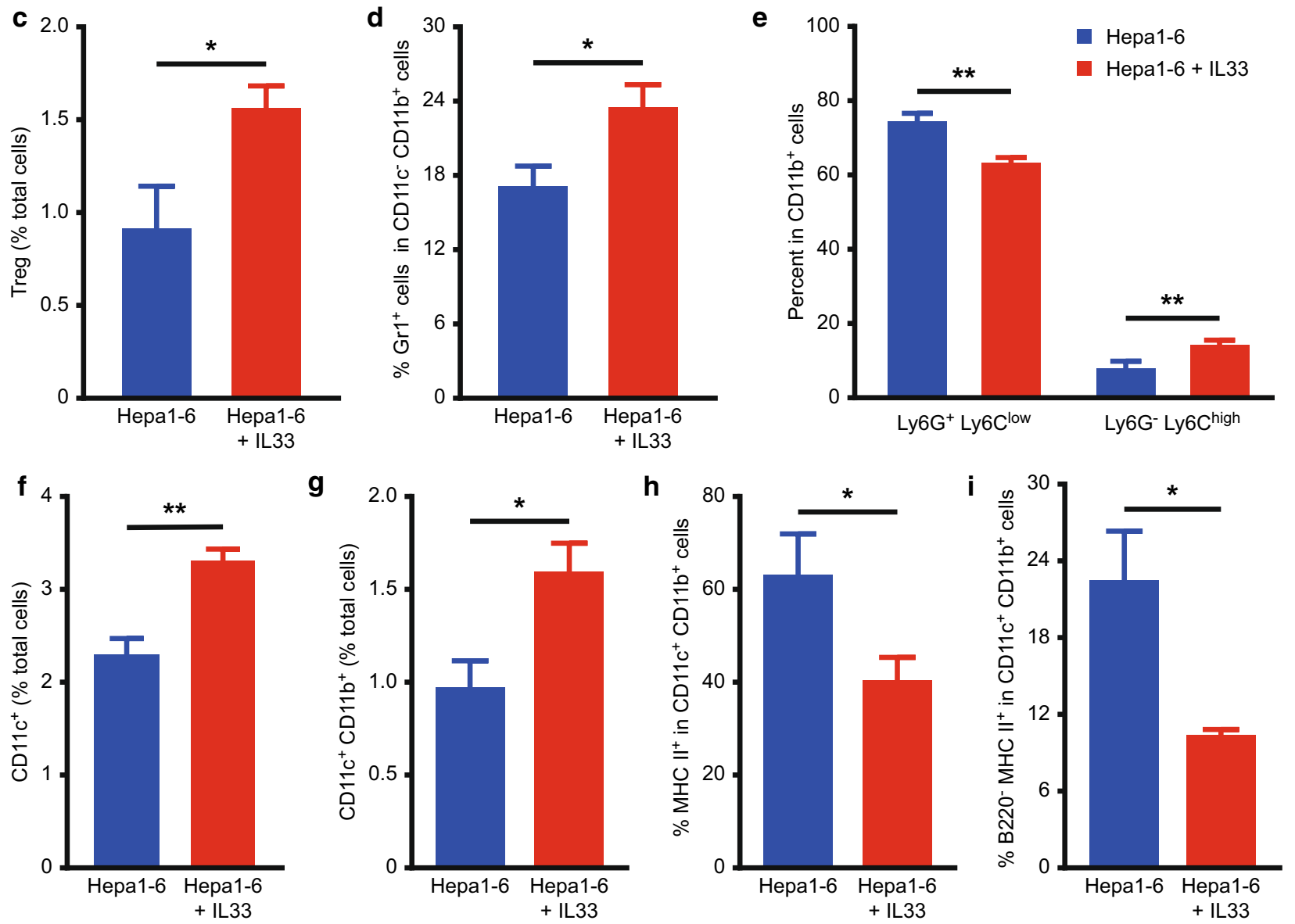

Fig. 3 IL-33 inhibited immune effector cells and mobilised immunosuppressive cells into the TME. Splenocytes and intrahepatic single-cell suspensions were harvested for flow cytometric analysis. a Percentages of tumour-infiltrating CD45 $5^{+}$leukocyte, $C D 3^{-} \mathrm{NK} 1.1^{+} \mathrm{NK}$ cells, CD4 ${ }^{+}$Foxp3 ${ }^{+}$ Tregs among total cells were determined by flow cytometry. $\mathbf{b}$ The percentages of activated $\mathrm{CD} 69^{+} \mathrm{CD} 4^{+} \mathrm{T}$ and $\mathrm{CD} 69^{+} \mathrm{CD} 8^{+} \mathrm{T}$ cells were presented. c IL-33 induced accumulation of splenic CD4 ${ }^{+}$Foxp3 ${ }^{+}$Tregs. D, e Flow cytometry was used to analyse Gr1, Ly6G, and Ly6C expression in gated $\mathrm{CD} 11 \mathrm{c}^{-} \mathrm{CD} 11 \mathrm{~b}^{+}$cells. $\mathbf{d} \mathrm{IL}-33$ treatment increased the accumulation of $\mathrm{CD} 11 \mathrm{c}^{-} \mathrm{CD} 11 \mathrm{~b}^{+} \mathrm{Gr} 1^{+}$MDSCs in tumour-bearing mice. e The percentages

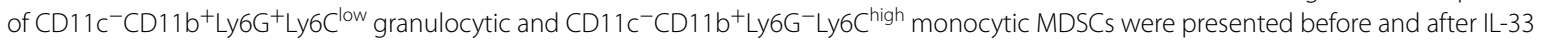
treatment. $\mathbf{f}-\mathbf{i}$ Flow cytometry was used to analyse $\mathrm{CD} 11 \mathrm{c}^{+}, \mathrm{CD} 11 \mathrm{c}^{+} \mathrm{CD} 11 \mathrm{~b}^{+}$in spleens, and $\mathrm{MHCl}{ }^{+}$and $\mathrm{B}_{2} 2 \mathrm{O}^{-} \mathrm{MHCll}^{+}$expression in gated $\mathrm{CD} 11 \mathrm{c}^{+} \mathrm{CD} 11 \mathrm{~b}^{+}$cells. IL-33 increased the percentage of $\mathrm{CD} 11 \mathrm{c}^{+}(\mathbf{f})$ and $\mathrm{CD} 11 \mathrm{c}^{+} \mathrm{CD} 11 \mathrm{~b}^{+}$cells $(\mathbf{g})$, while it decreased the percentage of conventional CD11 $\mathrm{c}^{+} \mathrm{CD} 11 \mathrm{~b}^{+} \mathrm{B} 220^{-} \mathrm{MHCl} \mathrm{I}^{+} \mathrm{DC}$ cells $(\mathbf{h}, \mathbf{i})$. TME tumour microenvironment, MDSCs myeloid-derived suppressor cells, DCs dendritic cells, IL interleukin, Tregs regulatory T cells 



f

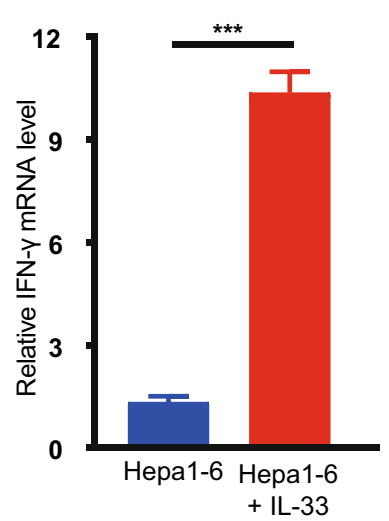

g b

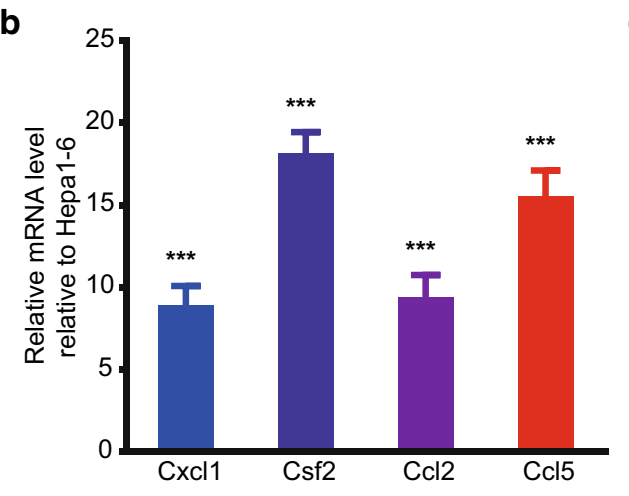

e
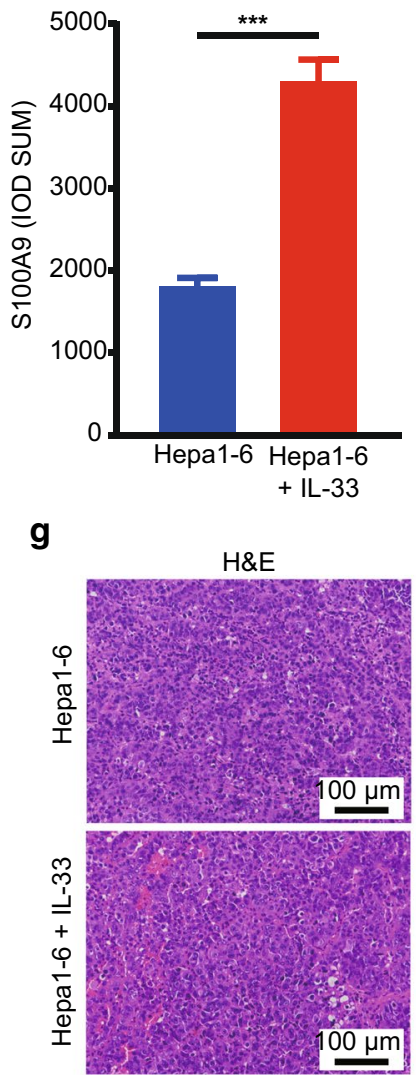

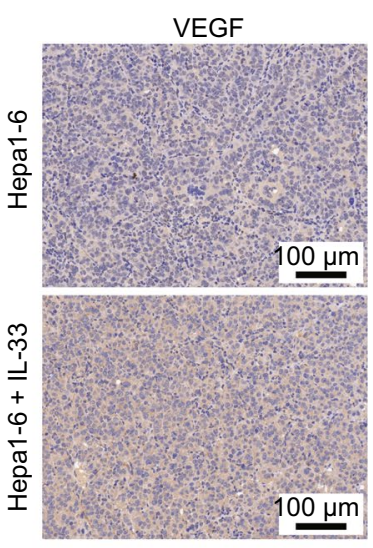

h

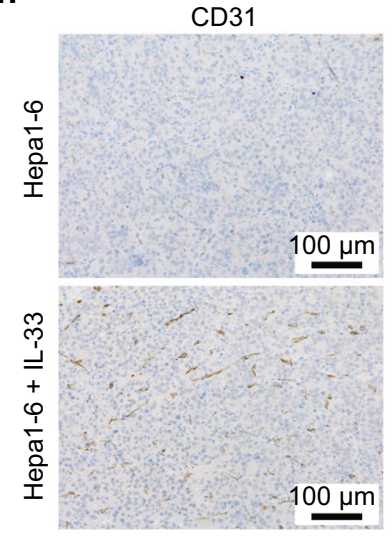

c
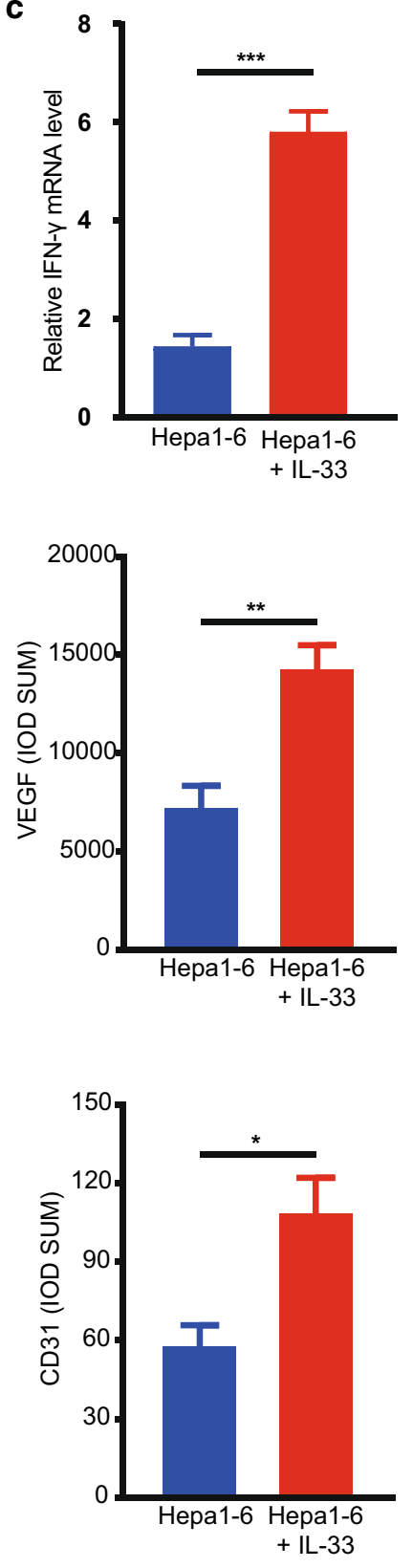

Fig. 4 IL-33 induced tumour-promoting cytokine and neomicrovessel formation. a The mRNA levels of tumour-promoting cytokines IL-6, IL-1 $\beta$, and TNF-a in tumour tissues from both groups of mice were presented. b Quantitative mRNA analysis of chemokines Csf2, CCl2, Ccl5, and Cxcl1 in tumours of IL-33-treated mice compared with those in PBS-treated wild-type mice. c Relative S100A9 mRNA levels and its immunohistochemical staining (d) were presented before and after IL-33 treatment. e-f VEGF was detected at the protein (e) and mRNA levels (f) in two groups. $\mathbf{g}$, $\mathbf{h}$ Tumour sections from both groups of mice were stained with H\&E (g) and IHC staining of CD31 (h) to detect microvessel formation. IHC immunohistochemistry, PBS phosphate-buffered saline, IL interleukin, VEGF Vascular endothelial growth factor, TNF tumour necrosis factor

In addition, GSEA was conducted to search GO terms, KEGG pathways, and Reactome using the HCC TCGA database. In these ridge plots, many pathways involved in tumourigenesis and cell cycle were related to IL-33 alterations (Fig. $6 \mathrm{a}-\mathrm{c}$ ). Among these pathways, we listed the two most common functional gene sets enriched in 


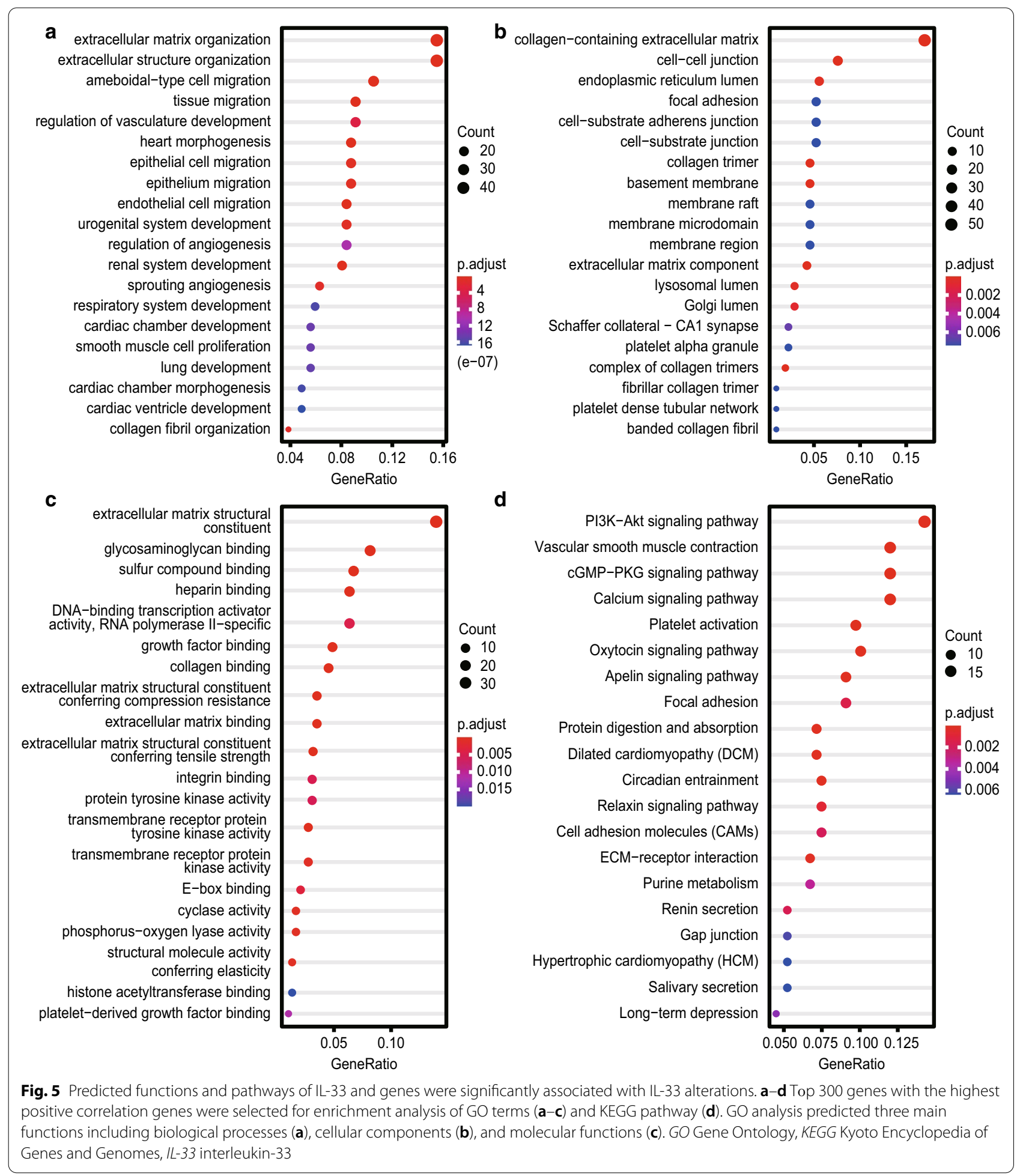

HCC with high IL-33 expression. GSEA-based KEGGenrichment plots showed that the gene signatures of the PI3K-Akt (Fig. 6d) and MAPK signalling pathways
(Fig. 6e) were highly correlated with IL-33 expression, which contributed to the tumourigenesis and progression of HCC. 


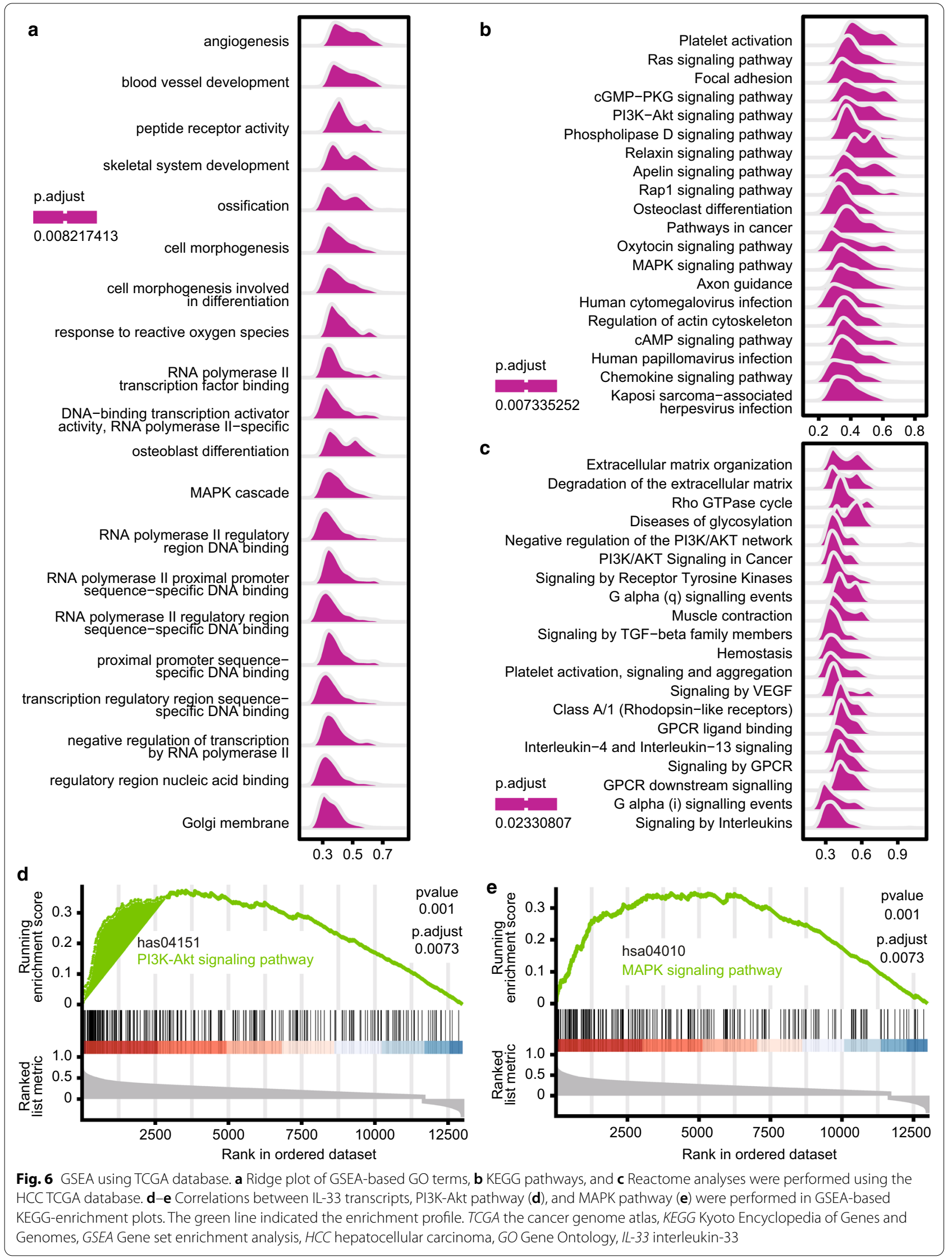




\section{Discussion}

Our study examined the effects of exogenous IL-33 on the biological characteristics of HCC in human tissues and in mice. We observed a higher IL-33 expression in liver cancer than in para-cancer tissues (Fig. 1a-c). Meanwhile, we verified that increased IL-33 expression was closely related to short OS and DFS in HCC patients (Fig. 1d, e). Studies have shown that the serum IL-33 [33] and ST2 [34] levels were associated with a worsened clinical prognosis of various diseases. Our study suggested that IL-33 may be a marker of poor prognosis in HCC patients. Repeated injection of IL-33 accelerated liver cancer growth in mice, as shown by the increased tumour size, weight, and Ki67 expression in the HCC tissue sections (Fig. 2a-f). However, IL-33 did not demonstrate Hepa1-6 cell proliferation in vitro, excluding its direct effect on tumour cells (Fig. 2g). Therefore, we hypothesized that IL-33 could play a role in tumour occurrence by influencing the TME [12], similar to its role in breast cancer [17].

Exogenous IL-33 increased CD $45^{+}$leukocyte immune cells and decreased NK cell infiltration in tumours (Fig. 3a). The percentage of activated $\mathrm{CD} 69^{+} \mathrm{CD} 8^{+} \mathrm{T}$ cells in the spleen was significantly downregulated in IL-33-treated mice (Fig. 3b). This reflects the important pathophysiological role of exogenous IL-33 in immune effector cells. Contrary to our findings, several studies have shown that IL-33 promotes type I immune response. Indeed, the antiviral immune response requires IL-33 signalling in $\mathrm{CD}^{+} \mathrm{T}$ cells [35]. IL-33 enhances NK and $\mathrm{CD}^{+} \mathrm{T}$ cell function, thereby, inhibiting tumour growth in transgenic mice [36]. High levels of IL-33 promote invasion of the TME by $\mathrm{CD} 8^{+} \mathrm{T}$ cells, NK, and NKT where they mediate their antitumour response [37]. The underlying cause of the difference between our findings and the corresponding of these studies remains unclear. We speculated that the immune effect of IL-33 may be influenced by its dose and microenvironment.

Several studies have supported the pro-tumour effect of IL-33, in line with our findings. Low levels or systemic IL-33 administration might induce immune tolerance in mice [38]. IL-33 administration promotes stemness in colon cancer cells by recruiting macrophages [39]. This may be because systemic injection of IL-33 elicits a broad immune response that promotes tumour growth in mice. MDSCs, Tregs, and immature DCS were treated as inhibiting antitumour immunity and promoting tumour angiogenesis [40]. IL-33 promoted the accumulation of MDSCs in the spleen of mice (Fig. 3d) and affected the frequency of monocytic and granulocytic MDSCs (Fig. 3e). However, the immunosuppressive ability of different subsets is not clear [41]. MDSCs are recruited from peripheral lymphoid organs to tumour sites, promoting the production of $\mathrm{CD} 4^{+} \mathrm{Foxp}^{+}$Tregs [42]. Our results showed increased DCs (Fig. 3f, g), whereas $\mathrm{CD} 11 \mathrm{c}^{+} \mathrm{CD} 11 \mathrm{~b}^{+} \mathrm{B} 220^{-} \mathrm{MHCII}^{+}$ conventional DCs decreased in response to IL-33 (Fig. 3i). Therefore, we speculated that IL-33 might increase plasmacytoid DCs in the TME, showing a powerful immunosuppressive property by inhibiting $\mathrm{T}$ cell activation or promoting Tregs development [43], which is consistent with the increase in Tregs frequency in our data (Fig. 3c). In addition, IL-33 induces immature DCs, which have poor stimulation and lower MHC II expression (Fig. 3h). IL-33 accelerated HCC progression by increasing the accumulation of immunosuppressive cells and inhibiting immune effector cells.

IL-33 enhanced the mRNA levels of pro-inflammatory factor TNF $\alpha$, which might stimulate tumour proliferation and angiogenesis (Fig. 4a). Further exploration revealed that chemokines (e.g. Cxcl1), which might favour the recruitment of myeloid cells into the TME, were significantly increased after IL-33 treatment (Fig. 4b). Once myeloid cells were recruited into the TME, pro-inflammatory cytokines that promote tumour proliferation were secreted [44]. Thus, increased S100A9 was found at the RNA and protein levels after IL-33 treatment (Fig. 4c, d), which may provide a pre-metastatic niche that could lead to tumour occurrence. In addition, IL-33 induced angiogenesis and vascular permeability, as demonstrated in a study of a murine asthma surrogate [45]. In our IHC staining data, CD31 and VEGF expression was significantly increased in HCC tissues after treatment with IL-33 (Fig. 4e, h). This was consistent with the higher VEGF levels, as observed in the PCR test (Fig. 4f), and the higher microvascular density (Fig. 4g) observed in the experimental group.

IL-33 is considered to be a reactive inducer of the immune system to inflammation and malignancy. Studies have shown that the presence of some inflammatory factors could also affect the biological function of IL-33. IL-2 and IL-33 synergistically induce IFN- $\gamma$ and enhance IL-33-driven immune response. High levels of IL-33 in the presence of pathogen-associated molecular pattern-induced IL-12 promote type I anti-tumour immune response [46]. In the presence of immunosuppressive factors (e.g. tumour growth factor- $\beta$ ), tumour stromal IL-33 plays an immunosuppressive role through Tregs and MDSCs.

IL-33, as an effective vaccine adjuvant combined with human papilloma virus vaccine enhances anti-tumour immunity of $\mathrm{CD} 8^{+} \mathrm{T}$ cells in vivo [47]. In addition, the combination of IL-33 blockers with programmed death-1 monoclonal antibodies could successfully inhibit acute myeloid leukaemia, and its combination with imatinib could also prevent chronic myeloid leukaemia resistance [48]. The effect of antibody drugs against IL-33 could be examined through clinical trials for asthma and other 
diseases. IL-33 mediates the invasion of tumour-associated fibroblasts promoting the development of head and neck squamous carcinoma in the TME [49], suggesting that IL-33 may be a key mediator between the stromal cells and tumour. However, the manner in which IL-33 expression regulates tumour epithelial and stromal cells remains unclear. Considering the dual role of IL-33 in cancer, it might be considered carefully in drug development as a target. In particular, IL-33 has the potential to cause inflammation and cancer.

\section{Conclusions}

In this study, we examined the effect of exogenous IL-33 on the biological characteristics of hepatocellular carcinoma in humans and in mice. We found that the overall survival of patients with high IL-33 expression was significantly shortened, suggesting that IL-33 may be a marker of poor prognosis in HCC patients. IL-33 favoured lymphocyte invasion of the tumour microenvironment, thus, promoting tumour growth and angiogenesis. The mechanism of IL-33 was explained in terms of tumour microenvironment remodelling, secretion of factors promoting tumour proliferation, and microvascular density. IL-33 may be a key tumour promoter that promotes the proliferation and tumourigenicity of HCC. Considering that IL-33 could play a dual role in cancer, it might be considered carefully in drug development as a target.

\section{Supplementary Information}

The online version contains supplementary material available at https://doi. org/10.1186/s12967-020-02661-w.

Additional file 1: Table S1. The primers used in the study.

Additional file 2: Figure S1. Exogenous IL-33 leaded to accelerate HCC growth.

Additional file 3: Figure S2. IL-33 did not affect effector or naive T cells and mRNA levels of IFN- $\gamma$.

\section{Abbreviations}

IL-33: Interleukin-33; HCC: Hepatocellular carcinoma; NK: Natural killer; DCs: Dendritic cells; cDCs: Conventional dendritic cells; OS: Overall survival time; DFS: Disease-free survival; MDSCs: Myeloid-derived suppressor cells; GO: Gene Ontology; KEGG: Kyoto Encyclopedia of Genes and Genomes; ILC2: Group 2 innate lymphoid cells; Tregs: Regulatory T cells; TME: Tumour microenvironment; MHC: Major histocompatibility complex; IHC: Immunohistochemistry.

\section{Acknowledgments}

We give our sincere gratitude to the reviewers for their valuable suggestions.

\section{Authors' contributions}

CW designed the experiments and drafted the manuscript. WW performed the experimentation and analyses of data. JW and MJ conceived and coordinated the study and helped to draft the manuscript. All authors read and approved the final manuscript.

\section{Funding}

This work was supported by grants from the National Key R\&D Plan (2018YFC1313400).

\section{Availability of data and materials}

The data that support the findings of this study are available from the corresponding author upon reasonable request.

\section{Ethics approval and consent to participate}

All animal studies, such as mouse care and experimental procedures were reviewed by the Animal Ethics Committee of The Third Affiliated Hospital of Soochow University. The studies involving human tissue samples were approved by the ethics committee of the Third Affiliated Hospital of Soochow University and all patients provided informed consent for participation.

\section{Consent for publication}

Not applicable.

\section{Competing interests}

The authors declare that they have no competing interests.

\section{Author details}

${ }^{1}$ Department of Tumour Biological Treatment, The Third Affiliated Hospital of Soochow University, Changzhou, Jiangsu, China. ${ }^{2}$ Department of Oncology, The Third Affiliated Hospital of Soochow University, 185 Juqian Street, Changzhou 213003, Jiangsu, China.

Received: 17 September 2020 Accepted: 3 December 2020

Published online: 11 December 2020

\section{References}

1. Schmitz J, Owyang A, Oldham E, Song Y, Murphy E, McClanahan TK, et al. IL-33, an interleukin-1-like cytokine that signals via the IL-1 receptorrelated protein ST2 and induces T helper type 2-associated cytokines. Immunity. 2005;5:479-90. https://doi.org/10.1016/j.immuni.2005.09.015.

2. Zhao YN, Li H, Zhao C, Liu GH. ST2 silencing aggravates ventricular remodeling and chronic heart failure in rats by mediating the IL-33/ST2 axis. J Tissue Eng Regen Med. 2020. https://doi.org/10.1002/term.3091.

3. Zhao XY, Zhou L, Chen Z, Ji Y, Peng X, Qi L, et al. The obesity-induced adipokine SST2 exacerbates adipose T and ILC2 depletion and promotes insulin resistance. Sci Adv. 2020;20:eaay6191. https://doi.org/10.1126/ sciadv.aay6191.

4. Kaur D, Chachi L, Gomez E, Sylvius N, Singh SR, Ramsheh MY, et al. ST2 expression and release by the bronchial epithelium is downregulated in asthma. Allergy. 2020. https://doi.org/10.1111/all.14436.

5. Wang Y, Chen Z, Huang Y, Yafei L, Tu S. Prognostic Significance of serum interleukins and soluble ST2 in Traditional Chinese Medicine (TCM) syndrome-differentiated rheumatoid arthritis. Med Sci Monit Int Med J Exp Clin Res. 2018. https://doi.org/10.12659/msm.907540.

6. Izadi D, Layton TB, Williams L, MCCann F, Cabrita M, Santo Al, et al. Identification of TNFR2 and IL-33 as therapeutic targets in localized fibrosis. Sci Adv. 2019;12:eaay0370. https://doi.org/10.1126/sciadv.aay0370.

7. Tu L, Yang L. IL-33 at the Crossroads of Metabolic Disorders and Immunity. Front Endocrinol. 2019. https://doi.org/10.3389/fendo.2019.00026.

8. Larsen K, Minaya M, Vaish V, Peña M. The role of IL-33/ST2 pathway in tumorigenesis. Int J Mol Sci. 2018. https://doi.org/10.3390/ijms19092676.

9. Griesenauer B, Paczesny S. The ST2/IL-33 axis in immune cells during inflammatory diseases. Front Immunol. 2017. https://doi.org/10.3389/ fimmu.2017.00475.

10. Drake LY, Kita H. IL-33: biological properties, functions, and roles in airway disease. Immunol Rev. 2017;1:173-84. https://doi.org/10.1111/imr.12552.

11. Krysko O, Teufelberger A, Van Nevel S, Krysko DV, Bachert C. Protease/antiprotease network in allergy: the role of Staphylococcus aureus proteaselike proteins. Allergy. 2019;11:2077-86. https://doi.org/10.1111/all.13783.

12. Shen JX, Liu J, Zhang GJ. Interleukin-33 in malignancies: friends or foes? Front Immunol. 2018. https://doi.org/10.3389/fimmu.2018.03051.

13. Fournié J, Poupot M. The pro-tumorigenic IL-33 involved in antitumor immunity: a Yin and Yang cytokine. Front Immunol. 2018. https://doi. org/10.3389/fimmu.2018.02506.

14. Schmieder A, Multhoff G, Radons J. Interleukin-33 acts as a pro-inflammatory cytokine and modulates its receptor gene expression in highly metastatic human pancreatic carcinoma cells. Cytokine. 2012;2:514-21. https://doi.org/10.1016/j.cyto.2012.06.286. 
15. Gao X, Wang X, Yang Q, Zhao X, Wen W, Li G, et al. Tumoral expression of IL-33 inhibits tumor growth and modifies the tumor microenvironment through CD8+ T and NK cells. J Immunol (Baltimore, Md:1950). 2015;1:438-45. https://doi.org/10.4049/jimmunol.1401344.

16. Luo P, Deng S, Ye H, Yu X, Deng Q, Zhang Y, et al. The IL-33/ST2 pathway suppresses murine colon cancer growth and metastasis by upregulating CD40 L signaling. Biomed Pharmacother Biomed Pharmacother. 2020. https://doi.org/10.1016/j.biopha.2020.110232.

17. Jovanovic IP, Pejnovic NN, Radosavljevic GD, Pantic JM, Milovanovic MZ, Arsenijevic NN. Interleukin-33/ST2 axis promotes breast cancer growth and metastases by facilitating intratumoral accumulation of immunosuppressive and innate lymphoid cells. Int J Cancer. 2014;7:1669-82. https://doi.org/10.1002/ijc.28481.

18. Zhang Y, Davis C, Shah S, Hughes D, Ryan JC, Altomare D, et al. IL-33 promotes growth and liver metastasis of colorectal cancer in mice by remodeling the tumor microenvironment and inducing angiogenesis. Mol Carcinogenesis. 2017;1:272-87. https://doi.org/10.1002/mc.22491.

19. Van der Jeught K, Sun Y, Fang Y, Zhou Z, Jiang H, Yu T, et al. ST2 as checkpoint target for colorectal cancer immunotherapy. JCI Insight. 2020. https://doi.org/10.1172/jci.insight.136073.

20. Eissmann MF, Dijkstra C, Jarnicki A, Phesse T, Brunnberg J, Poh AR, et al. IL-33-mediated mast cell activation promotes gastric cancer through macrophage mobilization. Nat Commun. 2019;1:2735. https://doi. org/10.1038/s41467-019-10676-1.

21. Wei ZH, Li YY, Huang SQ, Tan ZQ. Genetic variants in IL-33/ST2 pathway with the susceptibility to hepatocellular carcinoma in a Chinese population. Cytokine. 2019. https://doi.org/10.1016/j.cyto.2018.03.036.

22. Yang Y, Andersson P, Hosaka K, Zhang Y, Cao R, Iwamoto H, et al. The PDGF-BB-SOX7 axis-modulated IL-33 in pericytes and stromal cells promotes metastasis through tumour-associated macrophages. Nat Commun. 2016. https://doi.org/10.1038/ncomms11385.

23. Brunner SM, Rubner C, Kesselring R, Martin M, Griesshammer E, Ruemmele $P$, et al. Tumor-infiltrating, interleukin-33-producing effectormemory CD8(+) T cells in resected hepatocellular carcinoma prolong patient survival. Hepatology (Baltimore, MD). 2015;6:1957-67. https:// doi.org/10.1002/hep.27728.

24. Jin Z, Lei L, Lin D, Liu Y, Song Y, Gong H, et al. IL-33 released in the liver inhibits tumor growth via promotion of CD4 and CD8 T cell responses in hepatocellular carcinoma. J Immunol (Baltimore, Md:1950). 1950;2018(12):3770-9. https://doi.org/10.4049/jimmunol.1800627.

25. Ha E, Pe S. Primary carcinoma of the liver: a study of 100 cases among 48,900 necropsies. Cancer. 1954;3:462-503. https://doi. org/10.1002/1097-0142(195405)7:3\%3c462::aid-cncr282007 0308\%3e3.0.co;2-e

26. Peng D, Kryczek I, Nagarsheth N, Zhao L, Wei S, Wang W, et al. Epigenetic silencing of TH1-type chemokines shapes tumour immunity and immunotherapy. Nature. 2015;7577:249-53. https://doi.org/10.1038/ nature 15520.

27. Livak KJ, Schmittgen TD. Analysis of relative gene expression data using real-time quantitative PCR and the 2(-Delta Delta C(T)) Method. Methods (San Diego, Calif). 2001;4:402-8. https://doi.org/10.1006/ meth.2001.1262.

28. Qin L, Dominguez D, Chen S, Fan J, Long A, Zhang M, et al. Exogenous IL-33 overcomes T cell tolerance in murine acute myeloid leukemia. Oncotarget. 2016;38:61069-80. https://doi.org/10.18632/oncotarget .11179

29. Kobelt D, Zhang C, Clayton-Lucey IA, Glauben R, Voss C, Siegmund B, et al. Pro-inflammatory TNF-a and IFN- $\gamma$ promote tumor growth and metastasis via induction of MACC1. Front Immunol. 2020. https://doi. org/10.3389/fimmu.2020.00980.

30. Acharyya S, Oskarsson T, Vanharanta S, Malladi S, Kim J, Morris PG, et al. A CXCL1 paracrine network links cancer chemoresistance and metastasis. Cell. 2012;1:165-78. https://doi.org/10.1016/j.cell.2012.04.042.

31. Chen Y, Sumardika I, Tomonobu N, Kinoshita R, Inoue Y, lioka H, et al. Critical role of the MCAM-ETV4 axis triggered by extracellular S100A8/A9 in breast cancer aggressiveness. Neoplasia (New York, NY). 2019;7:627-40. https://doi.org/10.1016/j.neo.2019.04.006.

32. Liu J, Wang W, Wang L, Chen S, Tian B, Huang K, et al. IL-33 Initiates vascular remodelling in hypoxic pulmonary hypertension by upregulating HIF-1 $\mathrm{a}$ and VEGF expression in vascular endothelial cells. EBioMedicine. 2018. https://doi.org/10.1016/j.ebiom.2018.06.003.
33. Gong J, Zhu Y, Yu J, Jin J, Chen M, Liu W, et al. Increased serum interleukin-33 concentrations predict worse prognosis of aneurysmal subarachnoid hemorrhage. Clin Chim Acta Int J Clin Chem. 2018. https ://doi.org/10.1016/j.cca.2018.08.011.

34. Zhang Z, Wang H, Zhang L, Crew R, Zhang N, Liu X, et al. Serum levels of soluble ST2 and IL-10 are associated with disease severity in patients with IgA nephropathy. J Immunol Res. 2016. https://doi. org/10.1155/2016/6540937.

35. Bonilla WV, Fröhlich A, Senn K, Kallert S, Fernandez M, Johnson S, et al. The alarmin interleukin-33 drives protective antiviral CD8+ T cell responses. Science (New York, NY). 2012;6071:984-9. https://doi. org/10.1126/science.1215418.

36. Gao K, Li X, Zhang L, Bai L, Dong W, Gao K, et al. Transgenic expression of IL-33 activates CD8(+) T cells and NK cells and inhibits tumor growth and metastasis in mice. Cancer Lett. 2013;2:463-71. https://doi. org/10.1016/j.canlet.2013.03.002.

37. Zhang L, Kerkar SP, Yu Z, Zheng Z, Yang S, Restifo NP, et al. Improving adoptive $T$ cell therapy by targeting and controlling IL-12 expression to the tumor environment. Mol Ther J Am Soc Gene Ther. 2011;4:751-9. https://doi.org/10.1038/mt.2010.313.

38. Lu B, Yang M, Wang Q. Interleukin-33 in tumorigenesis, tumor immune evasion, and cancer immunotherapy. J Mol Med (Berlin, Germany). 2016:5:535-43. https://doi.org/10.1007/s00109-016-1397-0.

39. Fang M, Li Y, Huang K, Qi S, Zhang J, Zgodzinski W, et al. IL33 promotes colon cancer cell stemness via JNK activation and macrophage recruitment. Can Res. 2017;10:2735-45. https://doi.org/10.1158/0008-5472. can-16-1602.

40. Chen C, Tan L, Zhu W, Lei L, Kuang Y, Liu P, et al. Targeting myeloidderived suppressor cells is a novel strategy for anti-psoriasis therapy. Mediat Inflamm. 2020. https://doi.org/10.1155/2020/8567320.

41. Tcyganov E, Mastio J, Chen E, Gabrilovich D. Plasticity of myeloidderived suppressor cells in cancer. Curr Opin Immunol. 2018. https:// doi.org/10.1016/j.coi.2018.03.009.

42. Namdar A, Mirzaei R, Memarnejadian A, Boghosian R, Samadi M, Mirzaei $\mathrm{H}$, et al. Prophylactic DNA vaccine targeting Foxp3 regulatory T cells depletes myeloid-derived suppressor cells and improves antimelanoma immune responses in a murine model. Cancer Immunol Immunother CII. 2018;3:367-79. https://doi.org/10.1007/s0026 2-017-2088-6.

43. Bergeron A, El-Hage F, Kambouchner M, Lecossier D, Tazi A. Characterisation of dendritic cell subsets in lung cancer micro-environments. Eur Respir J. 2006:6:1170-7. https://doi.org/10.1183/09031936.06.00114205.

44. Lim S, Yuzhalin A, Gordon-Weeks A, Muschel R. Tumor-infiltrating monocytes/macrophages promote tumor invasion and migration by upregulating S100A8 and S100A9 expression in cancer cells. Oncogene. 2016:44:5735-45. https://doi.org/10.1038/onc.2016.107.

45. Shan S, Li Y, Wang J, Lv Z, Yi D, Huang Q, et al. Nasal administration of interleukin-33 induces airways angiogenesis and expression of multiple angiogenic factors in a murine asthma surrogate. Immunology. 2016;1:83-91. https://doi.org/10.1111/imm.12589.

46. Yang Q, Li G, Zhu Y, Liu L, Chen E, Turnquist H, et al. IL-33 synergizes with TCR and IL-12 signaling to promote the effector function of CD8+ T cells. Eur J Immunol. 2011;11:3351-60. https://doi.org/10.1002/ eji.201141629.

47. Villarreal DO, Wise MC, Walters JN, Reuschel EL, Choi MJ, Obeng-Adjei $\mathrm{N}$, et al. Alarmin IL-33 acts as an immunoadjuvant to enhance antigenspecific tumor immunity. Cancer Res. 2014;6:1789-800. https://doi. org/10.1158/0008-5472.can-13-2729.

48. Levescot A, Flamant S, Basbous S, Jacomet F, Féraud O, Bourgeois EA, et al. BCR-ABL-induced deregulation of the IL-33/ST2 pathway in CD34+ progenitors from chronic myeloid leukemia patients. Cancer Res. 2014;10:2669-76. https://doi.org/10.1158/0008-5472.can-13-2797.

49. Chen SF, Nieh S, Jao SW, Wu MZ, Liu CL, Chang YC, et al. The paracrine effect of cancer-associated fibroblast-induced interleukin-33 regulates the invasiveness of head and neck squamous cell carcinoma. J Pathol. 2013;2:180-9. https://doi.org/10.1002/path.4226.

\section{Publisher's Note}

Springer Nature remains neutral with regard to jurisdictional claims in published maps and institutional affiliations. 